REVIEW ARTICLE

\title{
Factors Influencing Prescribing Decisions of Physicians: A Review
}

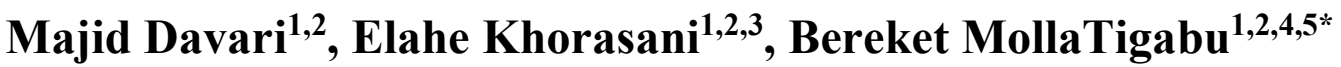

\section{OPEN ACCESS}

Citation: Majid Davari, Elahe Khorasani, Bereket MollaTigabu. Factors Influencing Prescribing Decisions of Physicians: A Review. Ethiop J Sci. 2018; 28 (6):795. doi: http://dx. doi.org/10.4314/ejhs.v28i6.15

Received: January 10, 2018

Accepted: April 20,2018

Published: November 1, 2018

Copyright: (C) 2018 Majid D, et al. This is an open access article distributed under the terms of the Creative Commons Attribution License, which permits unrestricted use, distribution, and reproduction in any medium, provided the original author and source are credited.

Funding: Nil

Competing Interests: The authors declare that this manuscript was approved by all authors in its form and that no competing interest exists.

Affiliation and Correspondence:

${ }^{1}$ Department of Pharmacoeconomics and Pharmaceutical Administration, Faculty of Pharmacy, Tehran University of Medical Sciences, Tehran, Iran

${ }^{2}$ Pharmaceutical Research Center, Tehran University of Medical Sciences ${ }^{3}$ Faculty of Pharmacy, Students' Scientific Research Center, Tehran University of Medical Sciences, Tehran, Iran

${ }^{4}$ Tehran University of Medical Sciences, International Campus ${ }^{5}$ Haramaya University, School of Pharmacy, Ethiopia

*Email: bereke2005@gmail.com

\begin{abstract}
BACKGROUND: The pharmaceutical bill is increasing at an alarming rate. The physician practice variation has a pronounced effect on healthcare spending. A number of factors can influence the prescribing behavior of physicians. The aim of this review was to identify the factors affecting the prescribing decision of physicians.
\end{abstract}

METHODS: Electronic databases including Scopus, PubMed/MEDLINE CENTRAL, Cochrane Libraries and Google scholar were searched systematically for literatures on factors influencing prescribing decisions of physicians from 2000 to 2016. There was no restriction on the study designs.

RESULTS: Thirty-three studies met the inclusion criteria from 1122 search results. A total of 33 factors were identified. The most frequent factors were patients' clinical condition, pharmaceutical industries, physician attributes, patient preference and cost of medicine.

CONCLUSION: Physicians' personal attributes, cost of the medicine and pharmaceutical industries' marketing and promotion strategies were mostly mentioned to influence prescribing decision. The identified factors showed that prescribing is not only geared for patient benefit, but also towards personal interest. The use of valid and reliable practice guidelines could reduce the negative impact of wide ranges of factors and promote the rational prescribing effectively.

KEYWORDS: prescribing behavior, prescribing decision, guideline, physician, systematic review

\section{INTRODUCTION}

Prescription medicines have become a major component of health systems worldwide. Per capita pharmaceutical expenditures in 2005/2006 ranged from US\$ 7.61 in low-income countries to US\$ 431.6 in high-income countries, with considerable variation between income groups in each country (1). On average, the use of pharmaceuticals in hospitals and other health care facilities raises the pharmaceutical bill by around $20 \%$ (2). The rise in pharmaceutical expenditure is the result of the amalgamated effect of several factors including national and international pharmaceutical regulations, pricing policies, the influence of 
pharmaceutical companies, innovation of new drug delivery systems, the emergence of new pharmaceuticals for the treatment of previously untreated conditions and the prescribers' decision (3-5).

Physicians are the primary decision makers on healthcare resources. Physicians' prescribing decisions are the key for hospitals dominance over the health sector market players; pharmaceutical companies' market share; and payers target to curb costs $(6,7)$. The variation in physician practice explains the difference in expenditure in the health sector $(8,9)$. Patient outcome also varies with practice variations $(9,10)$. The physician practice variation has a pronounced effect on healthcare spending increment. However, the connection between healthcare spending and outcomes is loose $(4,6)$. The physicians' practice significantly varies in medicine prescribing and laboratory procedures ordering $(11,12)$.

The prescribing decision is the result of a multitude of intertwined factors such as the educational background of prescribers, the working environment and so on (13-15). Factors influencing prescribers' decisions are the most important input to develop practice guidelines, healthcare policy and to devise a regulation for the pharmaceutical market. In addition, the pivotal-position of physicians makes the study of factors which influence prescribing decision of tremendous worth. Therefore, highlighting factors influencing prescribing decision helps to devise a structured way to rationalize patient care process and healthcare expenditure. The aim of this review was to identify the factors affecting prescribing decision of physicians.

\section{METHODS}

Search strategy: Electronic databases (PubMed/MEDLINE CENTRAL, Scopus, Cochrane Libraries and Google scholar) were searched from 2000 to 2016 . The search was done by combining the following keywords with Boolean operators "AND" and "OR": Prescribing, Prescription, factor, determinant, behavior, practice, preferences, inappropriate, optimal, pattern, decisions and suggest. Searching in each database was adapted to databases characteristics, and additionally Medical Subject Headings (MeSH) were considered for PubMed.

Eligibility criteria: The major selection criteria were: (1) factors influencing prescribing decision should be the main objective, (2) studies should be original articles, (3) the full text should be available and provide enough information, (4) the studies should be written in English, and (5) published from 2000 to 2016.

Selection of articles: The titles and abstracts of all records were screened by one reviewer. Then, the full texts were selected based on the inclusion criteria by two reviewers, independently. Discrepancies were settled by discussion and consensus including a third reviewer.

Data abstraction process: Two reviewers, using standardized format, separately extracted the following information: authors' name, date of publication, study design, aim of the study, physician's specialty, type of medicines, and identified factors.

Validity of selected articles: The heterogeneity of the reviewed studies hampers the use of the validated tools for quality assessment. Nevertheless, the full texts were appraised based on the following criteria, and disagreements were solved by discussion:

1. Did the study have sound objective?

2. Did the study mentioned factors influencing prescribing decision clearly?

3. Did the study clearly describe the setting and data sources?

4. Did the study use reliable methods?

5. Did the study discuss the validity and the limitations of the results?

Data synthesis: The recognized factors affecting prescribing decision were organized in a table.

\section{RESULTS}

Selection and characteristics of the studies: The search strategy identified 1122 records, and 36 articles were finally selected (Figure 1). 


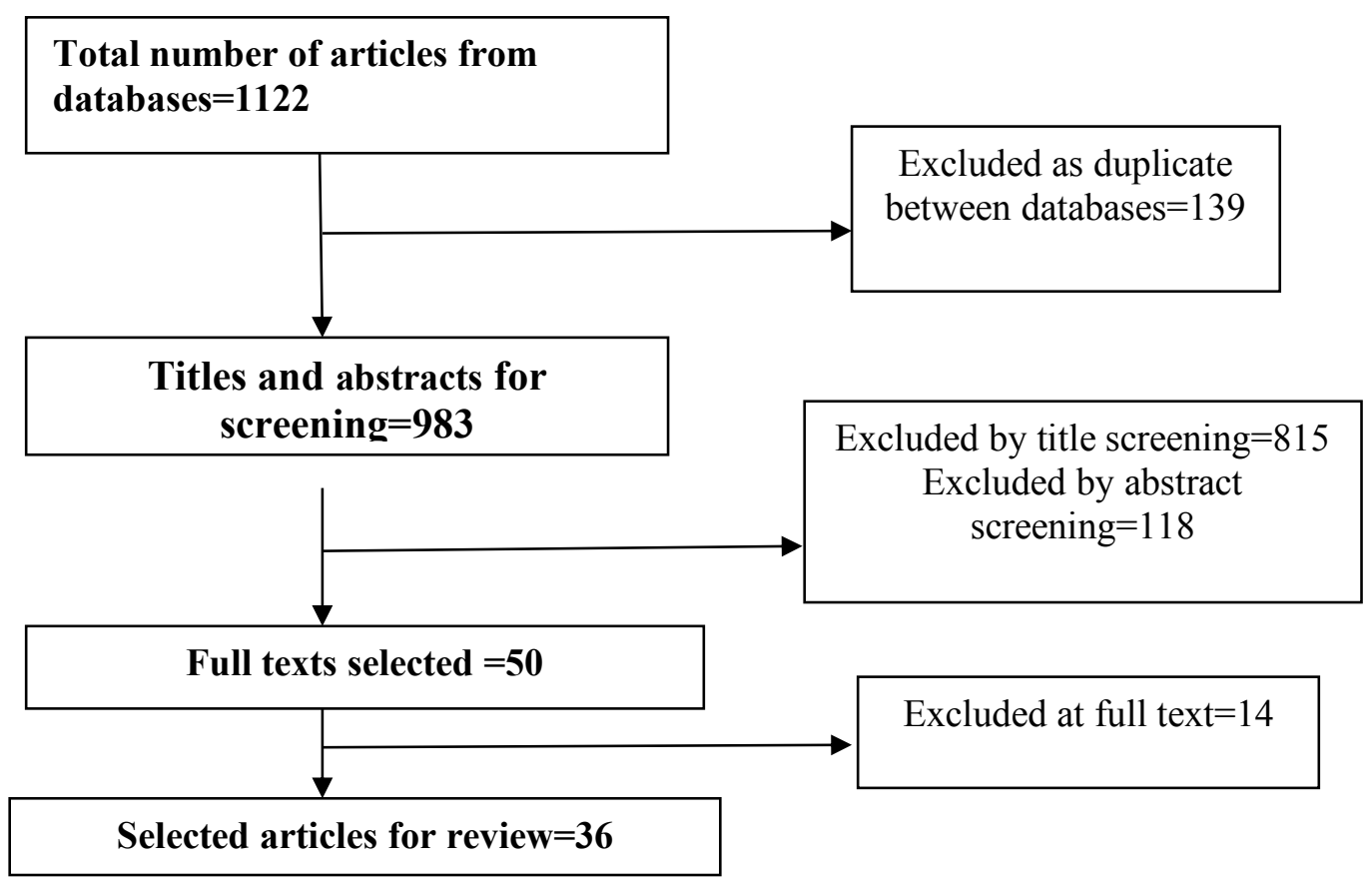

Figure 1: Bibliographical searches and inclusion process

Validity of selected studies: All the included articles had clear objectives, mentioned factors influencing prescribing decision clearly, and described the setting and data sources. Five studies used small samples (11 to 32 study participants) (1620). Eleven studies did not describe the generalizability and limitation of their findings (16,18,21-29).

Factors influencing prescribing decision: A total of 33 factors were identified. Physicians' personal attributes, cost of treatment, pharmaceutical industries' and patients' preferences were the most frequently identified factors to influence prescribing decisions (Table 1).

\section{DISCUSSION}

This was a review on the factors influencing prescribing decisions of physicians. Prescribers take the lion's share in rational pharmaceutical use. Prescribers decide the indication of the medicine based on the patients' condition. The clinical condition of the patient including the sign and symptoms, co-morbid conditions and uncertain diagnosis are some of the points looked by prescribers before prescribing $(17,20,26,31$, $35,36,44)$. A change in prescribing decision may also happen when physicians become in a difficult condition to identify the clinical indication of medicines or face a fear of complications $(52,53)$. Incomplete clinical pictures influence prescribers to change their prescribing decision (54). The clinical effectiveness and safety of pharmaceuticals are often considered to achieve the goal of therapy and enhance the patient compliance. Previous exposure of prescribers to the medicine and its past clinical success has a big role in altering prescribing decision $(16,23,25$, $34,41,50)$. It was shown that the use of diagnostic procedures for identification of the clinical condition and valid clinical guidelines fosters the rational prescribing effectively $(19,20,25,32,37)$. 
Table 1: Factors influencing prescribing decision of physicians.

\begin{tabular}{|c|c|c|c|}
\hline $\begin{array}{l}\text { Serial } \\
\text { № }\end{array}$ & Identified factor & Articles & Frequency \\
\hline 1. & Personal attributes** & $\begin{array}{l}(19,23,26,29-32,35,38,39,41,46,48, \\
49,51)\end{array}$ & 15 \\
\hline 2. & cost of treatment & $(20,26,28-30,34,36-39,42,44,48)$ & 13 \\
\hline 3. & Patient preference & $\begin{array}{l}(20,23,25,26,28,30,32,36,37,39,44, \\
48)\end{array}$ & 12 \\
\hline 4. & Pharmaceutical industries & $(20,26,28,31,36,38,39,42,44,47,48)$ & 11 \\
\hline 5. & Head of the departments and colleagues & $(20,23,27,30,31,39,47,51)$ & 8 \\
\hline 6. & patient's or families expectation & $(18,19,23,33,38,47,50,51)$ & 8 \\
\hline 7. & Patient's clinical condition & $(23,26,34,35,41,43,50)$ & 7 \\
\hline 8. & Clinical effectiveness and safety of the drug & $(25,28,29,34,36,39,48)$ & 7 \\
\hline 9. & Practice guidelines and policies & $(19,21,23,29,32,42,48)$ & 7 \\
\hline 10. & Patients insurance coverage & $(17,35,36,39,47,51)$ & 6 \\
\hline 11. & $\begin{array}{l}\text { Willingness to involve patients in decision- } \\
\text { making }\end{array}$ & $(19,23,31,46,47,50)$ & 6 \\
\hline 12. & Drug's indication & $(26,33,34,42,47)$ & 5 \\
\hline 13. & Available resources and practice location & $(23,28,39,51)$ & 4 \\
\hline 14. & Pharmaceutical attributes* & $(28,36,47,51)$ & 4 \\
\hline 15. & Preferred Information sources & $(26,28,31,36)$ & 4 \\
\hline 16. & Socio-demography of patients & $(27,49,51)$ & 4 \\
\hline 17. & Diagnostic procedures & $(21,23,47)$ & 3 \\
\hline 18. & Financial incentives & $(21,39,41)$ & 3 \\
\hline 19. & Patients ease of access to drug therapy & $(19,21,43)$ & 3 \\
\hline 20. & Time constraint & $(20,32,43)$ & 3 \\
\hline 21. & Resistance and treatment failure & $(21,26)$ & 2 \\
\hline 22. & Patients past experience with medication & $(25,48)$ & 2 \\
\hline 23. & Higher ratio of specialists to general physicians & $(27,39)$ & 2 \\
\hline 24. & Political and administrative influence & $(23,39)$ & 2 \\
\hline 25. & Patient knowledge & $(27,33)$ & 2 \\
\hline 26. & Patient's ability to take the drug & $(42,47)$ & 2 \\
\hline 27. & Clinicians' professionals ethos & (19) & 1 \\
\hline 28. & Number of doctors or doctor per patient & (41) & 1 \\
\hline 29. & $\begin{array}{l}\text { Physicians general attitudes towards the health } \\
\text { system }\end{array}$ & (46) & 1 \\
\hline 30. & Preference for local company & (26) & 1 \\
\hline 31. & Curiosity about the drug & (26) & 1 \\
\hline 32. & Personal 'head-held' drug formulary & (20) & 1 \\
\hline 33. & participation in clinical trial & (39) & 1 \\
\hline
\end{tabular}

*the dose, frequency, rout of administration and monitoring requirement of the drug

**experience, specialty, continuous professional development and area of interest of physician

A number of factors associated with the working and external environment that influence prescribing decision were highlighted in this review. It is a well-established fact that learning organizations and organizational structures increase the performance of employees (55). Availability of diagnostic and pharmaceutical resources in the organization could also influence the prescribing decision of physicians $(27,34,35,48,50)$. Pharmaceutical companies try

to influence the prescribing decision of prescribers by creating a mutual benefit based relationship (39). The pharmaceutical companies 
need the relationship to show how differentiated their products are and to increase their market share. Pharmaceutical companies usually do faceto-face detailing, provide medicine samples, provide written evidence, organize meetings, organize medicine launches, sponsor continuous medical education and provide gifts $(5,15,56,57)$. The type of advertising and promotion strategies is dynamic based on the physicians' reactions (58).

Clinical guideline development needs considerable heedfulness. Clinical guidelines that limit the discretion of prescribers will have doubtful implementation. It was revealed that physicians' involvement in hospital decision making process and development of hospital specific guidelines influence their prescribing decision (37). Physicians adhere more to the guidelines which their reflection was considered (32). Furthermore, feedback on the prescribing behavior based on agreed and reflected criteria improves the prescribing behavior more than mere distribution of guidelines $(32,59,60)$.

The physicians' attributes which include the clinical experience, specialty, continuous professional development and practice decision was the most frequently mentioned prescriber related factor. Clinical experience outlined as a factor to influence prescribing decision by most of the reviewed articles $(16,18,26,33,43,44,47)$. The exposure of physicians for different class of medicines and patient outcome are expected to increase with increased clinical experience and years of service. Hoever, a single study claimed that the quality of care decrease with increased clinical experience (61). Experience leads to a personal, informal medicine list, which may conflict with new guidelines (22). Specialist physicians' influence on prescribing decisions is expected to be high. Especially, in new medicine prescribing, most of the general practitioners are dependent on what was said by specialists (62). Physicians' perceptions of patient expectation influence their prescribing behavior (17), which is a stronger predictor of prescribing than patient perception(63). Physicians prescribe not to risk their relationship with patients when they perceive prescription is required (64). The information sources used by physicians have an important role in altering their prescribing decisions $(16,41,43,44,50)$. Although medical reference books and scientific literatures have a large theoretical importance, colleagues, clinical meetings and medical representatives are key sources of information used to prescribe new medicines (65). Information from pharmaceutical companies increases awareness on available medicines in the market. However, this information may turn physicians to high prescribers, high cost prescribers and low prescribing quality practitioners (66). Physicians' interest in a particular area and involvement in clinical trial are also important factors for new medicine prescribing (67).

In the current review a number of factors associated with the patient or the care givers were identified: the socio-demographic status, knowledge of patient about medicines, expectation and request to a particular treatment. The patient socio-demographics such as age, sex, social status has to be considered for better quality of care $(23,27,36,47)$. The knowledge of the patient on pharmaceutical products makes the patient request for a specific medication and alters patient expectations $(17,23,68)$. Generally, patients who expect prescription are more likely to have it $(69,70)$. Patient's pressure on physicians may lead to unnecessary prescribing and referral(63); but, the transition from the old paternalistic care to engagement of patients in decision making has increased the role of patients as an actor in decision making (71). Some studies showed that the involvement of patients in their care selection made physicians to change prescribing decision(69,70). Likewise, selfmedication practice towards antibiotics has made physicians to let the patient continue the unnecessary antibiotics to prevent resistance or to change the regimen to the more potent medicine due to the perception of resistance $(19,45)$.

The other factors identified are associated with the economic conditions: cost, insurance and financial incentives. The cost of a medicine to a patient is usually considered by physicians during prescribing $(16,21,22,26,31,34,35,41,44,48,50)$. Insurance, in general, was found to influence the 
selection of type and quantity of health care utilization and also improve health (72). The level of reimbursement of pharmaceuticals affects the prescribing decision of physicians. Insured patients consume more health care service than uninsured patients with a lower expenditure (73). The financial incentives for the prescriber are motives that influence the prescribing behavior and could increase induced demand (19). Financial incentives can be given by lower copayments for patients who choose medicines preferred by the payer (74). Financial incentives can also be achieved by physician payment modalities and health care financing systems. Capitation payment for each patient registered had shown a reduction in prescription costs (75).

Our findings showed that many factors can influence the prescribing decisions of physicians. These factors can be used in policy development to enhance the prescribing decision of prescribers. Factors may or may not give chance for change. Demographic characteristics and socioeconomic factors give a little room for improvement $(56,76)$. However, factors like knowledge, educational level, experience, the number of practicing professionals, cost sharing and guidelines can be modified to influence prescribing behavior.

The review included only articles published in the English language which might introduce bias. The studies included in the review had a different study design, data collection, analysis technique and many of them were done with a few classes of medicines. The factors level of influence on the prescribing decision was not included in this review.

Physician's personal attributes, cost of the medicine, and pharmaceutical industries' marketing and promotion strategies were mostly mentioned to influence prescribing decision. The identified factors showed prescribing is not only geared for patient benefit, but also towards physician's interest. The use of valid and reliable practice guidelines could reduce the negative impact of wide ranges of factors and promote the rational prescribing effectively. Studies on causative relationship between identified factors and prescribing decision may be a very effective research area for further studies.

\section{REFERENCES}

1. Lu Y, Hernandez P, Abegunde D, Edejer T. The world medicines situation 2011. Medicine expenditures World Health Organization, Geneva. 2011.

2. OECD. Health at a Glance 2011. OECD Indicators, OECD Publishing, Paris DOI: https://doi org/101787/health_glance-2015en Accessed February. 2015;15:2016.

3. Ali S, Chambers A, Johnson DW, Newton AS, Vandermeer B, Williamson $\mathrm{J}$, et al. Reported practice variation in pediatric pain management: a survey of Canadian pediatric emergency physicians. Canadian Journal of Emergency Medicine. 2014;16(5):352-60.

4. Blumenthal D, Stremikis K, Cutler D. Health care spending - a giant slain or sleeping? $n$ engl j med., 2013;396(26):2551-7.

5. Hossain M, Kawsar S, Tanmy T. Assessment of influencing factors on prescription practices of physicians in Bangladesh. Int Res J Pharm., 2013;4.

6. Aaron HJ, Ginsburg PB. Is health spending excessive? If so, what can we do about it? Health Affairs, 2009;28(5):1260-75.

7. Bodenheimer T. High and rising health care costs. Part 3: the role of health care providers. Annals of Internal medicine, 2005;142(12_Part_1):996-1002.

8. Grytten J, Sørensen R. Practice variation and physician-specific effects. Journal of health economics, 2003;22(3):403-18.

9. Jain S, Elon LK, Johnson BA, Frank G, DeGuzman M. Physician practice variation in the pediatric emergency department and its impact on resource use and quality of care. Pediatric emergency care, 2010;26(12):902-8.

10. Ketcham JD, Baker LC, MacIsaac D. Physician practice size and variations in treatments and outcomes: evidence from Medicare patients with AMI. Health Affairs, 2007;26(1):195-205.

11. Mojtabai R. Diagnosing depression and prescribing antidepressants by primary care

DOI: http://dx.doi.org/10.4314/ejhs.v28i6.15 
physicians: the impact of practice style variations. Mental health services research, 2002;4(2):109-18.

12. Pietz K, O'malley KJ, Byrne M, Souchek J, Petersen N, Ashton CM. Physician-level variation in practice patterns in the VA healthcare system. Health Services and Outcomes Research Methodology, 2002;3(2):95-106.

13. Knight A. Patient-centred prescribing. Australian Prescriber, 2013;36(6):199-201.

14. Mikhael EM, Alhilali DN. Gift acceptance and its effect on prescribing behavior among Iraqi specialist physicians. Pharm Pharmacol., 2014;5:705-15.

15. Oshikoya KA, Oreagba I, Adeyemi O. Sources of drug information and their influence on the prescribing behaviour of doctors in a teaching hospital in Ibadan, Nigeria. Pan African Medical Journal. 2011;9(13).

16. Al-Areefi MA, Hassali MA. The role of pharmaceutical marketing and other factors in prescribing decisions: the Yemeni experience. Research in Social and Administrative Pharmacy, 2013;9(6):981-8.

17. Hoffman D, Botha J, Kleinschmidt I. An assessment of factors influencing the prescribing of antibiotics in Acute Respiratory Illness: A questionnaire study. South African Family Practice, 2003;45(6):20-4.

18. Marić NP, Stojiljković DJ, Pavlović Z, Jašović-Gašić M. Factors influencing the choice of antidepressants: a study of antidepressant prescribing practice at University Psychiatric Clinic in Belgrade. Vojnosanitetski pregled., 2012;69(4):308-13.

19. Reynolds L, McKee M. Factors influencing antibiotic prescribing in China: an exploratory analysis. Health policy, 2009;90(1):32-6.

20. van Buul LW, van der Steen JT, Doncker SM, Achterberg WP, Schellevis FG, Veenhuizen RB, et al. Factors influencing antibiotic prescribing in long-term care facilities: a qualitative in-depth study. $B M C$ geriatrics, 2014;14(1):136.
21. Abulhaj E, ELSamen AA, Alabbadi I. Investigating the factors affecting doctor's prescribing behavior in Jordan: Antihypertensive drugs as an example. European Journal of Social Sciences, 2013;38(3):38091.

22. Carthy P, Harvey I, Brawn R, Watkins C. A study of factors associated with cost and variation in prescribing among GPs. Family Practice, 2000;17(1):36-41.

23. Choi K-H, Park S-M, Lee J-H, Kwon S. Factors affecting the prescribing patterns of antibiotics and injections. Journal of Korean medical science, 2012;27(2):120-7.

24. Cutts C, Tett SE. Influences on doctors' prescribing: is geographical remoteness a factor? Australian Journal of Rural Health, 2003;11(3):124-30.

25. Kisa S. Factors that influence prescribing decisions among Turkish physicians. Clinical Research and Regulatory Affairs, 2006;23(3-4):177-89.

26. Ljungberg C, Lindblad ÅK, Tully MP. Hospital doctors' views of factors influencing their prescribing. Journal of evaluation in clinical practice, 2007;13(5):765-71.

27. Ridge G, Gossop M, Lintzeris N, Witton J, Strang J. Factors associated with the prescribing of buprenorphine or methadone for treatment of opiate dependence. Journal of substance abuse treatment, 2009;37(1):95100.

28. Senior ML, Williams H, Higgs G. Morbidity, deprivation and drug prescribing: factors affecting variations in prescribing between doctors' practices. Health \& place, 2003;9(4):281-9.

29. Steinke D, Bain D, MacDonald T, Davey P. Practice factors that influence antibiotic prescribing in general practice in Tayside. Journal of Antimicrobial Chemotherapy, 2000;46(3):509-12.

30. Britten N, Stevenson FA, Barry CA, Barber $\mathrm{N}$, Bradley CP. Misunderstandings in prescribing decisions in general practice: qualitative study. Bmj, 2000;320(7233):4848. 
31. Garrison GD, Levin GM. Factors affecting prescribing of the newer antidepressants. Annals of Pharmacotherapy, 2000;34(1):104.

32. Lagerløv P, Loeb M, Andrew M, Hjortdahl P. Improving doctors 9 prescribing behaviour through reflection on guidelines and prescription feedback: a randomised controlled study. Quality and Safety in Health Care, 2000;9(3):159-65.

33. Bjørner T, Lærum E. Factors associated with high prescribing of benzodiazepines and minor opiates. Scandinavian journal of primary health care, 2003;21(2):115-20.

34. Schumock GT, Walton SM, Park HY, Nutescu EA, Blackburn JC, Finley JM, et al. Factors that influence prescribing decisions. Annals of Pharmacotherapy, 2004;38(4):557-62.

35. Tan E, Yeo A, Tan V, Pavanni R, Wong M. Prescribing pattern in Parkinson's disease: are cost and efficacy overriding factors? International journal of clinical practice, 2005;59(5):511-4.

36. DeWitt EM, Glick HA, Albert DA, Joffe MM, Wolfe F. Medicare coverage of tumor necrosis factor $\alpha$ inhibitors as an influence on physicians' prescribing behavior. Archives of internal medicine, 2006;166(1):57-63.

37. Martens JD, Winkens RA, van der Weijden $\mathrm{T}$, de Bruyn D, Severens JL. Does a joint development and dissemination of multidisciplinary guidelines improve prescribing behaviour: a pre/post study with concurrent control group and a randomised trial. BMC health services research, 2006;6(1):145.

38. Raina PS, Gafni A, Bell S, Grant S, Sebaldt RJ, Fan A, et al. Is there a tension between clinical practice and reimbursement policy? The case of osteoarthritis prescribing practices in Ontario. Healthcare Policy, 2007;3(2):e128.

39. Anderson BL, Silverman GK, Loewenstein GF, Zinberg S, Schulkin J. Factors associated with physicians' reliance on pharmaceutical sales representatives. Academic Medicine, 2009;84(8):994-1002.
40. Crowe S, Tully MP, Cantrill JA. The prescribing of specialist medicines: what factors influence GPs' decision making? Family practice, 2009;26(4):301-8.

41. Theodorou M, Tsiantou V, Pavlakis A, Maniadakis N, Fragoulakis V, Pavi E, et al. Factors influencing prescribing behaviour of physicians in Greece and Cyprus: results from a questionnaire based survey. $B M C$ health services research, 2009;9(1):150.

42. Lewis PJ, Tully MP. The discomfort caused by patient pressure on the prescribing decisions of hospital prescribers. Research in Social and Administrative Pharmacy, 2011;7(1):4-15.

43. Magzoub M, Neyaz Y, Khoja T, Qureshi N, Haycox A, Walley T. Determinants of physicians' medication prescribing behaviour in primary care in Riyadh city, Saudi Arabia. Eastern Mediterranean Health Journal, 2011;17:160-6.

44. Rajendran S, Sajbel TA, Hartman TJ. Factors Involved in Making Decisions to Prescribe Medications for Psychiatric Disorders by Psychiatrists: A Survey Study. Psychiatric Quarterly, 2012;83(3):271-80.

45. Brookes-Howell L, Hood K, Cooper L, Little $\mathrm{P}$, Verheij T, Coenen S, et al. Understanding variation in primary medical care: a ninecountry qualitative study of clinicians' accounts of the non-clinical factors that shape antibiotic prescribing decisions for lower respiratory tract infection. BMJ open, 2012;2(4):e000796.

46. Solomon J, Raynor DK, Knapp P, Atkin K. The compatibility of prescribing guidelines and the doctor-patient partnership: a primary care mixed-methods study. Br J Gen Pract., 2012;62(597):e275-e81.

47. Chou C-Y, Hsu C-C, Chiang S-C, Ho C-C, Chou C-L, Wu M-S, et al. Association between physician specialty and risk of prescribing inappropriate pill splitting. PLOS one, 2013;8(7):e70113.

48. Kalkan A, Roback K, Hallert E, Carlsson P. Factors influencing rheumatologists' prescription of biological treatment in 
rheumatoid arthritis: an interview study. Implementation Science, 2014;9(1):153.

49. McKinlay JB, Trachtenberg F, Marceau LD, Katz JN, Fischer MA. Effects of patient medication requests on physician prescribing behavior: results of a factorial experiment. Medical care, 2014;52(4):294.

50. Kamuhabwa AA, Kisoma S. Factors influencing prescribing practices of medical practitioners in public and private health facilities in Dar es Salaam, Tanzania. Tropical Journal of Pharmaceutical Research, 2015;14(11):2107-13.

51. Horwood J, Cabral C, Hay AD, Ingram J. Primary care clinician antibiotic prescribing decisions in consultations for children with RTIs: a qualitative interview study. $\mathrm{Br} J \mathrm{Gen}$ Pract., 2016;66(644):e207-e13.

52. Hulscher ME, Grol RP, van der Meer JW. Antibiotic prescribing in hospitals: a social and behavioural scientific approach. The Lancet infectious diseases, 2010;10(3):16775.

53. Rodrigues AT, Roque F, Falcão A, Figueiras A, Herdeiro MT. Understanding physician antibiotic prescribing behaviour: a systematic review of qualitative studies. International journal of antimicrobial agents, 2013;41(3):203-12.

54. Anderson K, Stowasser D, Freeman C, Scott I. Prescriber barriers and enablers to minimising potentially inappropriate medications in adults: a systematic review and thematic synthesis. BMJ open, 2014;4(12):e006544.

55. LePore P, Tooker J. The influence of organizational structure on physician satisfaction: findings from a national survey. Effective Clinical Practice, 2000;3(2):62-8.

56. Ijoma U, Onwuekwe I, Onodugo O, Aguwa E, Ejim E, Onyedum C, et al. Effect of Promotional Strategies of Pharmaceutical Companies on Doctors' Prescription Pattern in South East Nigeria. TAF Preventive Medicine Bulletin, 2010;9(1).

57. Lotfi T, Morsi RZ, Rajabbik MH, Alkhaled L, Kahale L, Nass H, et al. Knowledge, beliefs and attitudes of physicians in low and middle-income countries regarding interacting with pharmaceutical companies: a systematic review. BMC health services research, 2016;16(1):57.

58. Fugh-Berman A, Ahari S. Following the script: how drug reps make friends and influence doctors. PLoS Medicine, 2007;4(4):e150.

59. Jamtvedt G, Young JM, Kristoffersen DT, O'Brien MA, Oxman AD. Audit and feedback: effects on professional practice and health care outcomes. Cochrane Database Syst Rev., 2006;2(2).

60. Rowe AK, de Savigny D, Lanata CF, Victora CG. How can we achieve and maintain highquality performance of health workers in low-resource settings? The Lancet, 2005;366(9490):1026-35.

61. Choudhry NK, Fletcher RH, Soumerai SB. Systematic review: the relationship between clinical experience and quality of health care. Annals of Internal medicine, 2005;142(4):260-73.

62. Prosser H, Almond S, Walley T. Influences on GPs' decision to prescribe new drugsthe importance of who says what. Family Practice, 2003;20(1):61-8.

63. Little P, Dorward M, Warner G, Stephens K, Senior J, Moore M. Importance of patient pressure and perceived pressure and perceived medical need for investigations, referral, and prescribing in primary care: nested observational study. Bmj, 2004;328(7437):444.

64. Stevenson FA, Greenfield SM, Jones M, Nayak A, Bradley CP. GPs' perceptions of patient influence on prescribing. Family Practice, 1999;16(3):255-61.

65. McGettigan P, Golden J, Fryer J, Chan R, Feely J. Prescribers prefer people: The sources of information used by doctors for prescribing suggest that the medium is more important than the message. British journal of clinical pharmacology, 2001;51(2):184-9.

66. Spurling GK, Mansfield PR, Montgomery BD, Lexchin J, Doust J, Othman N, et al. Information from pharmaceutical companies and the quality, quantity, and cost of 
physicians' prescribing: a systematic review. PLoS medicine, 2010;7(10):e1000352.

67. Lublóy Á. Factors affecting the uptake of new medicines: a systematic literature review. BMC health services research, 2014;14(1):469.

68. Robinson AR, Hohmann KB, Rifkin JI, Topp D, Gilroy CM, Pickard JA, et al. Direct-toconsumer pharmaceutical advertising: physician and public opinion and potential effects on the physician-patient relationship. Archives of Internal Medicine, 2004;164(4):427-32.

69. Cockburn J, Pit S. Prescribing behaviour in clinical practice: patients' expectations and doctors' perceptions of patients' expectations - a questionnaire study. Bmj, 1997;315(7107):520-3.

70. Macfarlane J, Holmes W, Macfarlane R, Britten N. Influence of patients' expectations on antibiotic management of acute lower respiratory tract illness in general practice: questionnaire study. Bmj, 1997;315(7117):1211-4.

71. Taylor K. Paternalism, participation and partnership - the evolution of patient centeredness in the consultation. Patient education and counseling, 2009;74(2):150-5.

72. Freeman JD, Kadiyala S, Bell JF, Martin DP. The causal effect of health insurance on utilization and outcomes in adults: a systematic review of US studies. Medical care, 2008;46(10):1023-32.

73. Al-Mohamadi A, Al-Harbi AM, Manshi AM, Rakkah MM. Medications prescribing pattern toward insured patients. Saudi Pharmaceutical Journal, 2014;22(1):27-31.

74. Huskamp HA, Deverka PA, Epstein AM, Epstein RS, McGuigan KA, Frank RG. The effect of incentive-based formularies on prescription-drug utilization and spending. New England Journal of Medicine, 2003;349(23):2224-32.

75. Chaix-Couturier C, Durand-Zaleski I, Jolly D, Durieux P. Effects of financial incentives on medical practice: results from a systematic review of the literature and methodological issues. International Journal for Quality in Health Care, 2000;12(2):13342.

76. Zahrani HSA. The impact of pharmaceutical promotions on primary health care physician's prescribing behaviour in KAMC in central region. Int $J$ Med Sci Public Health., 2014;3:358-64. 